\title{
Optimization of integrated multi-trophic aquaculture systems for the giant freshwater prawn Macrobrachium rosenbergii
}

\author{
Xuexing Dong ${ }^{1,2}$, Linlan $\mathrm{Lv}^{2}$, Weihong Zhao ${ }^{2}$, Yebing $\mathrm{Yu}^{2}$, Qigen Liu ${ }^{1, *}$ \\ ${ }^{1}$ College of Fisheries and Life Sciences, Shanghai Ocean University, Shanghai 201306, PR China \\ ${ }^{2}$ Key Laboratory for Aquaculture and Ecology of Coastal Pool of Jiangsu Province, Department of Ocean Technology, \\ Yancheng Institute of Technology, Yancheng, Jiangsu Province 224051, PR China
}

\begin{abstract}
Traditional monoculture farming of the giant freshwater prawn Macrobrachium rosenbergii causes a deterioration in water quality as a result of effluent discharge, leading to frequent disease outbreaks and environmental pollution. In the present study, the effects of integrated multitrophic aquaculture (IMTA) systems on the growth of $M$. rosenbergii and water quality were evaluated. Six treatments, with 4 replicates each, were used, including prawn monoculture (MP), prawn with aquatic plants (Lemna minor) (PP), prawn with silver carp Hypophthalmichthys molitrix (PF), prawn with mussels (Anodonta sp.) and H. molitrix (PMF), prawn with Anodonta sp. and L. minor (PMP) and prawn with Anodonta sp., L. minor and H. molitrix (PMPF). Growth rates of $M$. rosenbergii and physical, chemical and biological parameters were assessed every $10 \mathrm{~d}$ and on the last day of the $64 \mathrm{~d}$ experiment. Average weight gain in $M$. rosenbergii was highest in the PMPF group, although this was not statistically significant. There was also no significant difference in survival rate among treatments. Dissolved oxygen concentrations were significantly higher in the PMPF group, whereas total nitrogen and chlorophyll a concentrations were highest in the PF group. Compared to the MP group, stocking with $H$. molitrix (PF, PMF and PMPF) effectively reduced $\mathrm{PO}_{4}$-P. L. minor exhibited effective uptake of both $\mathrm{N}$ and $\mathrm{P}$. In contrast to the group stocked only with H. molitrix (PF), stocking with L. minor (PP and PMP groups) reduced phytoplankton biomass. In summary, culturing $M$. rosenbergii in a multitrophic PMPF system provides the potential for increased economic profits and ecological benefits.
\end{abstract}

KEY WORDS: Macrobrachium rosenbergii $\cdot$ Integrated multitrophic aquaculture $\cdot$ Specific growth rate $\cdot$ Water quality $\cdot$ Chlorophyll a

\section{INTRODUCTION}

The giant freshwater prawn Macrobrachium rosenbergii (De Man, 1879) is widely cultured in China and Southeast Asia, with an annual global production of over $500000 \mathrm{t}$ (FAO 2012). As the largest freshwater prawn in size and with strong resistance to disease, $M$. rosenbergii is becoming increasingly attractive as an aquaculture species around the world. Traditionally, prawn/shrimp have been intensively monocultured, which causes a deterioration in water quality and disease problems.

${ }^{*}$ Corresponding author: qgliu@shou.edu.cn
Jackson et al. (2003) found that feeds contributed $90 \%$ of the nitrogen $(\mathrm{N})$ input in shrimp ponds, with only $22 \%$ converted to body N, $14 \%$ remaining in the sediment and most of the remainder $(57 \%)$ discharged into the environment. Water quality deteriorates as a result of the uneaten feed and feces from the cultured species, and discharged effluents are among the major causes of widespread disease outbreaks in shrimp species. Effluent from shrimp ponds has also been speculated to be the main source of coastal pollution (Sansanayuth et al. 1996, Sun et al. 1997, Costanzo et al. 2004). Both of these issues are 
great challenges that need to be addressed for the sustainable development of the global aquaculture industry. An environmentally sustainable solution for prawn aquaculture that has shown promise is the use of integrated multitrophic aquaculture (IMTA) (Chopin et al. 2001, Neori et al. 2004, FAO 2006). IMTA combines, in the appropriate proportions, the cultivation of fed aquaculture species such as finfish/shrimp with organic extractive aquaculture species (e.g. shellfish/herbivorous fish) and inorganic extractive aquaculture species (e.g. seaweed or aquatic vascular plants) to create balanced systems for environmental sustainability, economic stability and social acceptability (FAO 2009).

The effects of IMTA have been investigated using various finfish/shrimp species in either open coastal waters or land-based systems and in both marine and freshwater systems (FAO 2009). Many studies have focused on IMTA for whiteleg shrimp Litopenaeus vannamei (Ramos et al. 2009, Cruz-Suárez et al. 2010, Yuan et al. 2010); however, few have assessed $M$. rosenbergii. Liu et al. (2014) studied the effects of silver carp Hypophthalmichthys molitrix and bighead carp H. nobilis and/or freshwater mussels (triangle snail mussel Hyriopsis cumingii Lea) on the performance of $M$. rosenbergii in ponds and demonstrated that the co-cultured filter-feeding carp led to an improvement in water quality. However, this study only adopted the integration of prawn and mussels without adding any aquatic plants into the system. Aquatic plants are often used to purify water by absorbing nutrients, and some plants additionally serve as food for $M$. rosenbergii. It is therefore important to explore the effects of aquatic plant integration into prawn culture systems, both on water quality and prawn growth, in order to develop an optimal IMTA system for $M$. rosenbergii. In the present study, we compared $M$. rosenbergii growth and water quality parameters across 6 aquaculture systems comprising different combinations of filter-feeding carp or mussels and floating aquatic plants via enclosure experiments. The objective was to develop an optimized IMTA system for $M$. rosenbergii culture to improve the sustainable development of shrimp culture in China.

\section{MATERIALS AND METHODS}

\section{Study site and species}

A total of 24 enclosures $(5 \times 3 \times 1.9 \mathrm{~m})$ were set up in the open water of a branch of the Yancheng Tongyu River, which flows through the Yancheng
Institute of Technology, Jiangsu Province, China. The enclosures were separated from both the surrounding water and the river beds with water-proof coated PVC cloth in order to ensure consistent environmental conditions. A feeding tray was also set up in each enclosure. The average water depth was kept at around $1.0 \mathrm{~m}$ during the experiment, and enclosures were aerated with a $1.5 \mathrm{~kW}$ roots blower. Larval Macrobrachium rosenbergii (6-8 g) and Hypophthalmichthys molitrix fingerlings (5-6 g) were purchased from a local fish farm, while mussels (Anodonta sp.) $(129.84 \pm 22.02 \mathrm{~g}$, mean $\pm \mathrm{SE})$ were purchased from a local market in Yancheng City, Jiangsu Province, China. An aquatic plant, common duckweed Lemna minor, was transplanted from a local lake.

\section{Experimental design}

To investigate the optimal IMTA system for $M$. rosenbergii, we established 6 groups with 4 replicates in each: Group I was the control monoculture prawn group (MP); Group II integrated prawn with aquatic plants (L. minor) (PP); Group III integrated prawn with fish (H. molitrix) $(\mathrm{PF})$; Group IV integrated prawn, mussels (Anodonta sp.) and H. molitrix (PMF); Group V integrated prawn, Anodonta sp. and L. minor (PMP), and Group VI integrated prawn, Anodonta sp., L. minor and H. molitrix (PMPF). $M$. rosenbergii in all 6 groups were stocked at $100 \mathrm{~g} \mathrm{~m}^{-2}$. The initial coverage of $L$. minor was kept at $5 \%$ of the surface area of each enclosure in the PP, PMP and PMPF groups. H. molitrix were stocked at 10 ind. enclosure $^{-1}$ in the PF, PMF and PMPF groups. Anodonta sp. were kept at 4 ind. enclosure ${ }^{-1}$ in the PMF, PMP and PMPF groups. The experiment was conducted over the course of $64 \mathrm{~d}$ from 19 July to 20 September 2014. Initial and final weights of the prawn, H. molitrix and Anodonta sp. in each enclosure were taken. The water temperature varied between 21.4 and $31.7^{\circ} \mathrm{C}$ during the experiment.

\section{Husbandry, water management and monitoring}

The prawn were fed 3 times a day (at approximately 06:00, 12:00 and 18:00 h) with a commercial feed (moisture $\leq 10 \%$; crude protein $\geq 38.0 \%$; crude fat $\geq 4.0 \%$ ). The feed ration was $3-5 \%$ of the estimated biomass of prawns and was determined according to the amount likely to be completely consumed within $1.5 \mathrm{~h}$. Feed ration was adjusted according to the weather conditions, feeding performance and 
growth of the prawn. No water exchanges were made within the enclosures during the experiment. Aeration was provided according to weather conditions (i.e. enclosures were aerated on cloudy and rainy days). $H$. molitrix and Anodonta sp. were not fed directly.

Every $10 \mathrm{~d}$, water samples were taken at 08:00 $\mathrm{h}$ to determine dissolved oxygen (DO), chemical oxygen demand $\left(\mathrm{COD}_{\mathrm{Mn}}\right)$, nitrate nitrogen $\left(\mathrm{NO}_{3}-\mathrm{N}\right)$, nitrite nitrogen $\left(\mathrm{NO}_{2}-\mathrm{N}\right)$, ammonium nitrogen $\left(\mathrm{NH}_{3}-\mathrm{N}\right)$, total nitrogen (TN), total phosphorus (TP), phosphate phosphorus $\left(\mathrm{PO}_{4}-\mathrm{P}\right)$ and total organic carbon (TOC) in each enclosure. Water samples for chlorophyll $a$ (chl a) were taken every $10 \mathrm{~d}$, starting on Day 20. DO and $\mathrm{pH}$ were determined in situ with a portable DO meter (YSI 58) and $\mathrm{pH}$ meter (Lovibond SD150D), respectively. TOC was determined after filtration with a multi N/C ${ }^{\circledR 2100 ~(A n a l y t i k ~ J e n a) ~ T O C ~ a n a-~}$ lyzer. $\mathrm{NO}_{2}-\mathrm{N}$ and $\mathrm{NH}_{3}-\mathrm{N}$ contents were immediately measured by a microcomputer multi-parameter water quality rapid tester (Lovibond ET7919). Water quality parameters including $\mathrm{COD}_{\mathrm{Mn}}, \mathrm{TN}, \mathrm{NO}_{3}-\mathrm{N}, \mathrm{TP}$ and $\mathrm{PO}_{4}-\mathrm{P}$ were determined within $24 \mathrm{~h}$ according to the standard methods of Jin \& Tu (1990). Chl a concentrations were determined photometrically after filtration onto Whatman GF/F glass fiber filters and extraction with acetone (Zhang \& Huang 1995).

\section{Calculations and statistics}

Growth performance of the prawn was determined by percentage weight gain $\left(W_{\mathrm{g}}\right)$ and specific growth rate (SGR). $W_{\mathrm{g}}$ was calculated as:

$$
W_{\mathrm{g}}=\left(W_{\mathrm{t}}-W_{0}\right) / W_{0} \times 100 \%
$$

where $W_{\mathrm{g}}$ refers to the average weight gained during the experiment, $W_{t}$ is the average weight of prawn at the end of the experiment, and $W_{0}$ is the initial average weight of prawn in each enclosure.

SGR was calculated as:

$\mathrm{SGR}=\left[\begin{array}{c}\mathrm{Ln}(\text { final weight })-\operatorname{Ln}(\text { initial weight }) \times 100] \\ / \text { culture period }(\text { in days })\end{array}\right.$

The survival rate of prawn was calculated as:

Survival $(\%)=($ no. of harvested individuals

/ no. of stocked individuals) $\times 100$

Data were analyzed using SPSS for Windows (version 17.0). Means of water quality parameters between treatments and the control were compared using 1-way ANOVA to evaluate the differences between monoculture and IMTA systems. Where main effects were significant, least significant difference tests determined which treatments differed significantly. Pearson's correlation analysis was performed on pairs of water quality parameters.

\section{RESULTS}

\section{Growth performance of Macrobrachium rosenbergii}

There were no statistically significant differences in $W_{\mathrm{g}}$ or survival rate among groups ( $\mathrm{p}>0.05$ ); however, the $W_{\mathrm{g}}$ and SGRs of $M$. rosenbergii were highest in the PMPF, where the $W_{\mathrm{g}}$ increased by $44.37 \%$ compared to the MP group. Yields of Hypophthalmichthys molitrix and Anodonta sp. were also highest in PMPF. Compared with PF and PMF, H. molitrix in the PMPF group increased yields by 45.54 and $24.19 \%$, respectively (Table 1). The survival rate in groups with Lemna minor was relatively higher than in other groups $(\mathrm{p}>0.05)$.

Table 1. Mean \pm SE weight gain of the prawn Macrobrachium rosenbergii and final weight of the prawns and output of carp and mussles (with shells) in different experimental treatments after $64 \mathrm{~d}$. Treatment groups are as follows; MP: monoculture prawn; PP: prawn in culture with aquatic plants (duckweed Lemna minor); PF: prawn with fish (silver carp Hypophthalmichthys molitrix); PMF: prawn with mussels (Anodonta sp.) and fish; PMP: prawn with mussels and aquatic plants; PMPF: prawn with mussels, aquatic plants and fish

\begin{tabular}{|c|c|c|c|c|c|c|c|}
\hline \multirow{2}{*}{ Group } & \multicolumn{5}{|c|}{ Macrobrachium rosenbergii } & \multirow{2}{*}{$\begin{array}{l}\text { Silver carp } \\
\text { output }(g)\end{array}$} & \multirow{2}{*}{$\begin{array}{c}\text { Anodonta sp. } \\
\text { output (g) }\end{array}$} \\
\hline & $\begin{array}{l}\text { Initial weight } \\
\text { (g) }\end{array}$ & $\begin{array}{l}\text { Final weight } \\
\qquad(g)\end{array}$ & $\begin{array}{l}\text { Weight gain } \\
(\%)\end{array}$ & $\begin{array}{l}\text { Specific growth } \\
\text { rate }\left(\% \mathrm{~d}^{-1}\right)\end{array}$ & $\begin{array}{l}\text { Survival rate } \\
\qquad \%)\end{array}$ & & \\
\hline MP & $7.07 \pm 0.86$ & $19.26 \pm 0.04$ & $172.11 \pm 0.59$ & $2.93 \pm 0.00$ & $72.96 \pm 4.92$ & & \\
\hline $\mathrm{PP}$ & $7.07 \pm 0.86$ & $18.18 \pm 3.88$ & $156.86 \pm 54.82$ & $2.81 \pm 0.39$ & $80.94 \pm 11.80$ & & \\
\hline $\mathrm{PF}$ & $7.07 \pm 0.86$ & $22.44 \pm 2.10$ & $216.93 \pm 29.69$ & $3.07 \pm 0.09$ & $68.02 \pm 3.69$ & $403 \pm 37.0$ & \\
\hline PMF & $7.07 \pm 0.86$ & $23.98 \pm 2.56$ & $238.69 \pm 36.20$ & $3.13 \pm 0.11$ & $62.21 \pm 7.92$ & $561 \pm 0.05$ & $307 \pm 93.6$ \\
\hline PMP & $7.07 \pm 0.86$ & $17.91 \pm 0.79$ & $153.03 \pm 11.27$ & $2.85 \pm 0.04$ & $84.27 \pm 3.10$ & $250 \pm 74.3$ & \\
\hline PMPF & $7.07 \pm 0.86$ & $22.96 \pm 4.16$ & $248.48 \pm 47.62$ & $3.07 \pm 0.17$ & $76.94 \pm 8.09$ & $740 \pm 37.0$ & $492 \pm 58.0$ \\
\hline
\end{tabular}




\section{Dynamics of water quality during the experiment}

Over the duration of the experiment, mean values for $\mathrm{DO}, \mathrm{pH}, \mathrm{TN}, \mathrm{NO}_{3}-\mathrm{N}, \mathrm{NH}_{3}-\mathrm{N}, \mathrm{PO}_{4}-\mathrm{P}$, chl $a$ and the TN:TP ratio were significantly different among groups ( $p<0.05$; Table 2). Mean concentrations of DO in the PMPF and PMP groups were significantly higher than those in MP, PP and PMP, as was the case for $\mathrm{pH}$. However, compared to the MP group, the mean concentrations of $\mathrm{NH}_{3}$ and $\mathrm{NO}_{2}-\mathrm{N}$ were significantly lower in PF, PMF and PMPF. The concentration of $\mathrm{PO}_{4}-\mathrm{P}$ was significantly higher in MP than in all other groups. Mean TN was significantly higher in the MP and PF groups, and the TN:TP ratio and chl a were greatest in the PF group ( $p<0.05)$.

\section{Effect of different treatments on water quality}

DO fluctuated from 2.5 to $9.9 \mathrm{mg} \mathrm{l}^{-1}$ during the culture period (Fig. 1A). We found significant differences across sampling times in DO within the PP, PMF and PMPF groups. Specifically, DO decreased on Day 20, then increased on Days 30 and 40 before finally decreasing again on Days 50 and 60. DO was significantly higher in the PMF group than in PP and PMP ( $\mathrm{p}<0.05$ ) on Day 10 and Day 20. The $\mathrm{pH}$ varied from 7.73 to 9.38 , and there were significant differences among the sampling times except within the MP group (Fig. 1B). Significant differences in $\mathrm{pH}$ were also found among groups, where the $\mathrm{pH}$ of the fish polyculture groups ( $\mathrm{PF}$ and $\mathrm{PMF}$ ) was significantly greater than that of the L. minor groups (PP and PMP) on Days 20, 30, 40 and 50. The concentration of COD gradually increased during the culture period (Fig. 1C). With the exception of the MP group, the COD concentrations on Days 30,50 and 60 were higher than on Day 10. On Day 40, the COD concentration in the MP group was significantly higher than in the other groups ( $p<0.05)$, but no significant differences among groups were found at other sampling times.

TOC concentration increased initially, then decreased in all groups during the culture period, with the greatest difference noticed between Day 20 and Day 50 in the PMF group (Fig. 1D). On Day 10, TOC within the PMF group was significantly higher than that of MP, PF and PMPF ( $p<0.05)$. No obvious difference was found among groups at other sampling times.

Overall, the concentration of TN showed an increasing trend in all groups during the culture period. The largest values were found on Day 50 in the MP and PF groups, and Day 40 in the PMP group, and these were significantly different from values on Day 10 (Fig. 2A). TN concentration in the PF group was significantly higher than in the PP, PMF, PMP and PMPF groups on Days 30, 50 and 60 ( $\mathrm{p}<0.05$ ). However, the $\mathrm{NO}_{3}-\mathrm{N}$ concentration gradually decreased at the start and then increased at the end of the culture period in the PMF, PMP and PMPF groups (Fig. 2B). Similar trends were observed in $\mathrm{NO}_{2}-\mathrm{N}$ (Fig. 2C). On Day 40, $\mathrm{NO}_{2}-\mathrm{N}$ concentrations in the PP, PF, PMF, PMP and PMPF groups were significantly lower than in the MP group. Meanwhile, $\mathrm{NH}_{3}-\mathrm{N}$ seemed to be stable during the culture period with the exception of the MP group (Fig. 2D).

There were significant differences in $\mathrm{PO}_{4}-\mathrm{P}$ (Fig. 2E) among the sampling times in all groups, and the same trend was seen in TP in the MP, PP, PMF, PMP

Table 2. Mean \pm SE water quality parameters over the entire duration of the culture. Different superscript letters within rows indicate significant $(\mathrm{p}<0.05)$ differences between groups. Treatment groups are defined in Table 1. DO: dissolved oxygen; COD: chemical oxygen demand; TOC: total organic carbon; TN: total nitrogen; TP: total phosphorus

\begin{tabular}{|c|c|c|c|c|c|c|}
\hline & MP & $\mathrm{PP}$ & $\mathrm{PF}$ & PMF & PMP & PMPF \\
\hline $\mathrm{DO}\left(\mathrm{mg} \mathrm{l}^{-1}\right)$ & $5.27 \pm 0.37^{\mathrm{bc}}$ & $5.05 \pm 0.25^{\mathrm{c}}$ & $6.05 \pm 0.26^{\mathrm{ab}}$ & $6.52 \pm 0.27^{\mathrm{a}}$ & $4.66 \pm 0.29^{c}$ & $6.18 \pm 0.26^{\mathrm{a}}$ \\
\hline $\mathrm{pH}$ & $8.50 \pm 0.07^{b}$ & $8.52 \pm 0.08^{b}$ & $8.84 \pm 0.07^{\mathrm{a}}$ & $8.93 \pm 0.05^{\mathrm{a}}$ & $8.41 \pm 0.08^{b}$ & $8.84 \pm 0.05^{\mathrm{a}}$ \\
\hline $\mathrm{COD}_{\mathrm{Mn}}\left(\mathrm{mg} \mathrm{l}^{-1}\right)$ & $11.14 \pm 1.27$ & $10.44 \pm 0.89$ & $8.82 \pm 0.99$ & $10.01 \pm 0.97$ & $9.95 \pm 0.87$ & $10.48 \pm 0.99$ \\
\hline $\mathrm{TOC}\left(\mathrm{mg} \mathrm{l}^{-1}\right)$ & $43.95 \pm 6.35$ & $44.44 \pm 4.46$ & $46.45 \pm 4.55$ & $50.90 \pm 5.98$ & $47.04 \pm 3.54$ & $35.95 \pm 3.76$ \\
\hline $\mathrm{TN}\left(\mathrm{mg} \mathrm{l}^{-1}\right)$ & $4.13 \pm 0.53^{\mathrm{a}}$ & $1.82 \pm 0.23^{b}$ & $4.79 \pm 0.66^{\mathrm{a}}$ & $1.96 \pm 0.27^{b}$ & $2.49 \pm 0.33^{b}$ & $1.79 \pm 0.28^{\mathrm{b}}$ \\
\hline $\mathrm{NO}_{3}-\mathrm{N}\left(\mathrm{mg} \mathrm{l}^{-1}\right)$ & $0.13 \pm 0.01$ & $0.12 \pm 0.01$ & $0.12 \pm 0.01$ & $0.10 \pm 0.01$ & $0.10 \pm 0.01$ & $0.11 \pm 0.01$ \\
\hline $\mathrm{NO}_{2}-\mathrm{N}\left(\mathrm{mg} \mathrm{l}^{-1}\right)$ & $0.14 \pm 0.03^{\mathrm{a}}$ & $0.09 \pm 0.02^{\mathrm{abc}}$ & $0.05 \pm 0.02^{\mathrm{c}}$ & $0.08 \pm 0.02^{\mathrm{bc}}$ & $0.11 \pm 0.02^{\mathrm{ab}}$ & $0.06 \pm 0.02^{\mathrm{bc}}$ \\
\hline $\mathrm{NH}_{3}-\mathrm{N}\left(\mathrm{mg} \mathrm{l}^{-1}\right)$ & $0.30 \pm 0.10^{\mathrm{a}}$ & $0.19 \pm 0.07^{\mathrm{ab}}$ & $0.08 \pm 0.03^{b}$ & $0.07 \pm 0.01^{\mathrm{b}}$ & $0.17 \pm 0.05^{\mathrm{ab}}$ & $0.08 \pm 0.02^{\mathrm{b}}$ \\
\hline $\mathrm{PO}_{4}-\mathrm{P}\left(\mathrm{mg} \mathrm{l}^{-1}\right)$ & $0.15 \pm 0.02^{\mathrm{a}}$ & $0.08 \pm 0.01^{\mathrm{b}}$ & $0.06 \pm 0.01^{\mathrm{bc}}$ & $0.05 \pm 0.01^{\mathrm{c}}$ & $0.09 \pm 0.01^{\mathrm{b}}$ & $0.08 \pm 0.01^{\mathrm{bc}}$ \\
\hline $\mathrm{TP}\left(\mathrm{mg} \mathrm{l}^{-1}\right)$ & $0.39 \pm 0.04$ & $0.33 \pm 0.05$ & $0.24 \pm 0.03$ & $0.29 \pm 0.05$ & $0.41 \pm 0.07$ & $0.39 \pm 0.06$ \\
\hline $\mathrm{N}: \mathrm{P}$ & $12.88 \pm 2.10^{\mathrm{b}}$ & $7.99 \pm 1.37^{b}$ & $26.80 \pm 4.39^{\mathrm{a}}$ & $11.40 \pm 2.74^{\mathrm{b}}$ & $11.60 \pm 2.96^{\mathrm{b}}$ & $8.29 \pm 2.31^{\mathrm{b}}$ \\
\hline Chl a $\left(\mu g l^{-1}\right)$ & $32.45 \pm 8.80^{\mathrm{bc}}$ & $19.57 \pm 2.64^{\mathrm{c}}$ & $51.54 \pm 9.50^{\mathrm{a}}$ & $30.84 \pm 3.99^{c}$ & $18.64 \pm 2.79^{\mathrm{c}}$ & $38.75 \pm 4.84^{\mathrm{ab}}$ \\
\hline
\end{tabular}



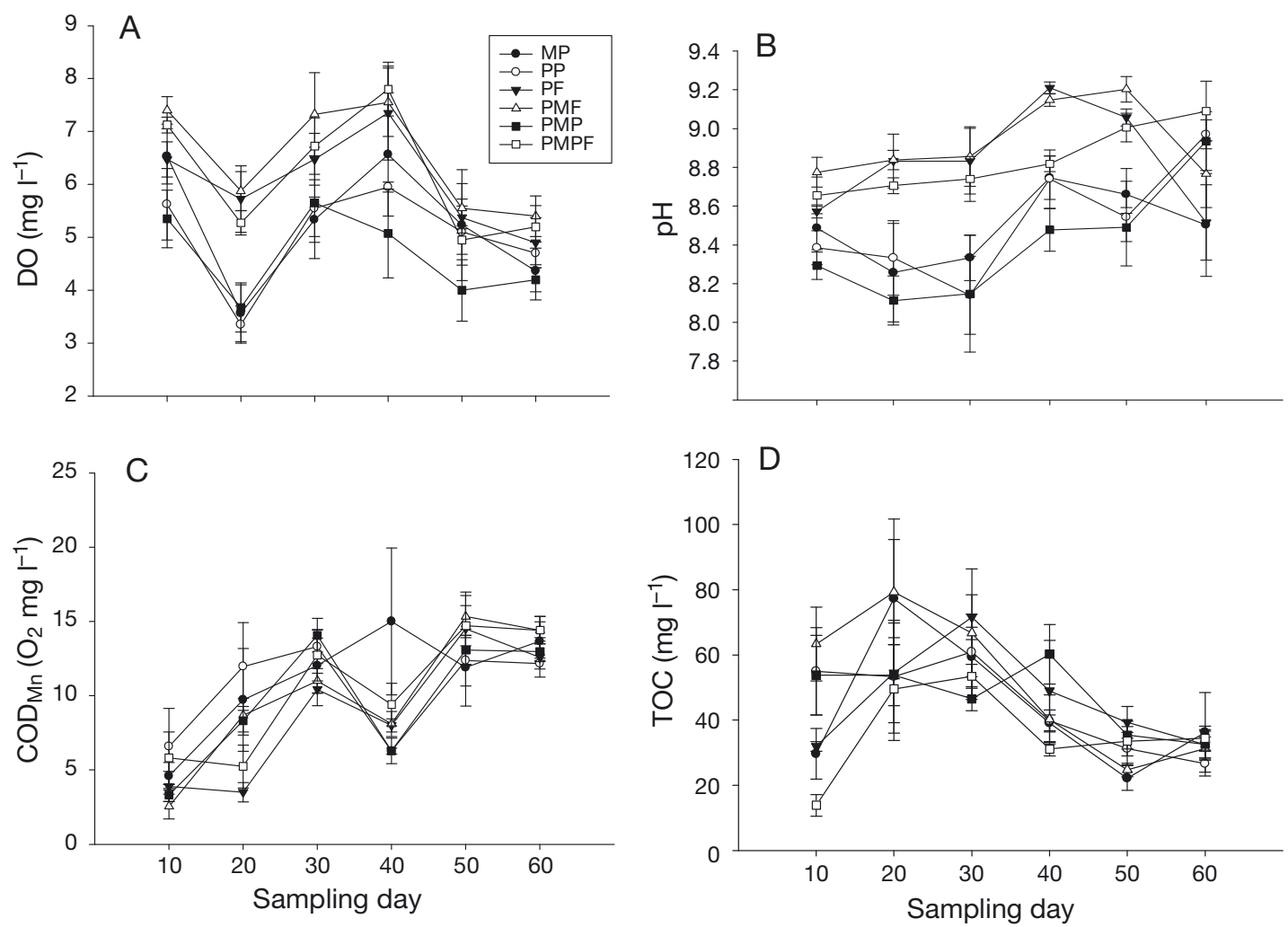

Fig. 1. Temporal dynamics of (A) dissolved oxygen (DO), (B) $\mathrm{pH},(\mathrm{C})$ chemical oxygen demand (COD $\mathrm{Mn}$ ) and (D) total organic carbon (TOC) in different treatments during the experiment. Data are presented as means \pm SE. Treatment groups are defined in Table 1

and PMPF groups (Fig. 2F). The concentrations of TP and $\mathrm{PO}_{4}-\mathrm{P}$ and the TN:TP ratio (Fig. 2G) initially increased, then decreased during the culture period. The TN:TP ratio in the group containing fish (PF) was significantly higher than in other groups on Days 30 and 50, and it was also higher than other groups, except the MP group, on Day 60. Significant differences between the MP group and other groups in $\mathrm{PO}_{4}$-P and TP started on Day 20 and Day 30, respectively. $\mathrm{PO}_{4}-\mathrm{P}$ concentrations in groups with fish $(\mathrm{PF}$, $\mathrm{PMF})$ were significantly lower than in the MP group on Days 20, 30, 40, 50 and 60 ( $<<0.05)$. On Day 30, TP concentrations in the PF and PMF groups were also obviously lower than in the MP group. At the completion of the culture period (Day 60), only $\mathrm{PO}_{4}-\mathrm{P}$ concentrations in polyculture groups were significantly lower than those in the MP group, and there were no significant differences in TP among groups.

Chl a concentrations first increased on Day 40, then decreased on Day 50 in all experimental groups (Fig. 3). By Day 60, chl a increased again across all groups except the MP group. Significant differences in chl a were observed in the PF group on Day 60, where concentrations were significantly higher than those in other groups.

\section{Correlation between chl $a$ and water quality parameters}

Chl $a$ in the MP group was not significantly correlated with the other major water quality parameters (Table 3). In contrast, chl a was positively correlated with $\mathrm{pH}, \mathrm{TN}$ and the TN:TP ratio, and significantly negatively correlated with TOC in the PP group. Chl a was significantly positively correlated with DO in the PF and PMF groups, and with $\mathrm{pH}$ in the PMP and PMPF groups.

\section{DISCUSSION}

\section{Weight gain}

The average weight gain of Macrobrachium rosenbergii in the PMPF increased by $44.37 \%$ compared to the control MP in our study, although the differences were not statistically significant between the treatment and control groups. This improvement in weight gain in the PMPF likely resulted from the improvement in water quality (relatively higher DO, lower $\mathrm{NO}_{2}-\mathrm{N}$ and $\mathrm{NH}_{3}-\mathrm{N}$ ) in the ponds from the pres- 

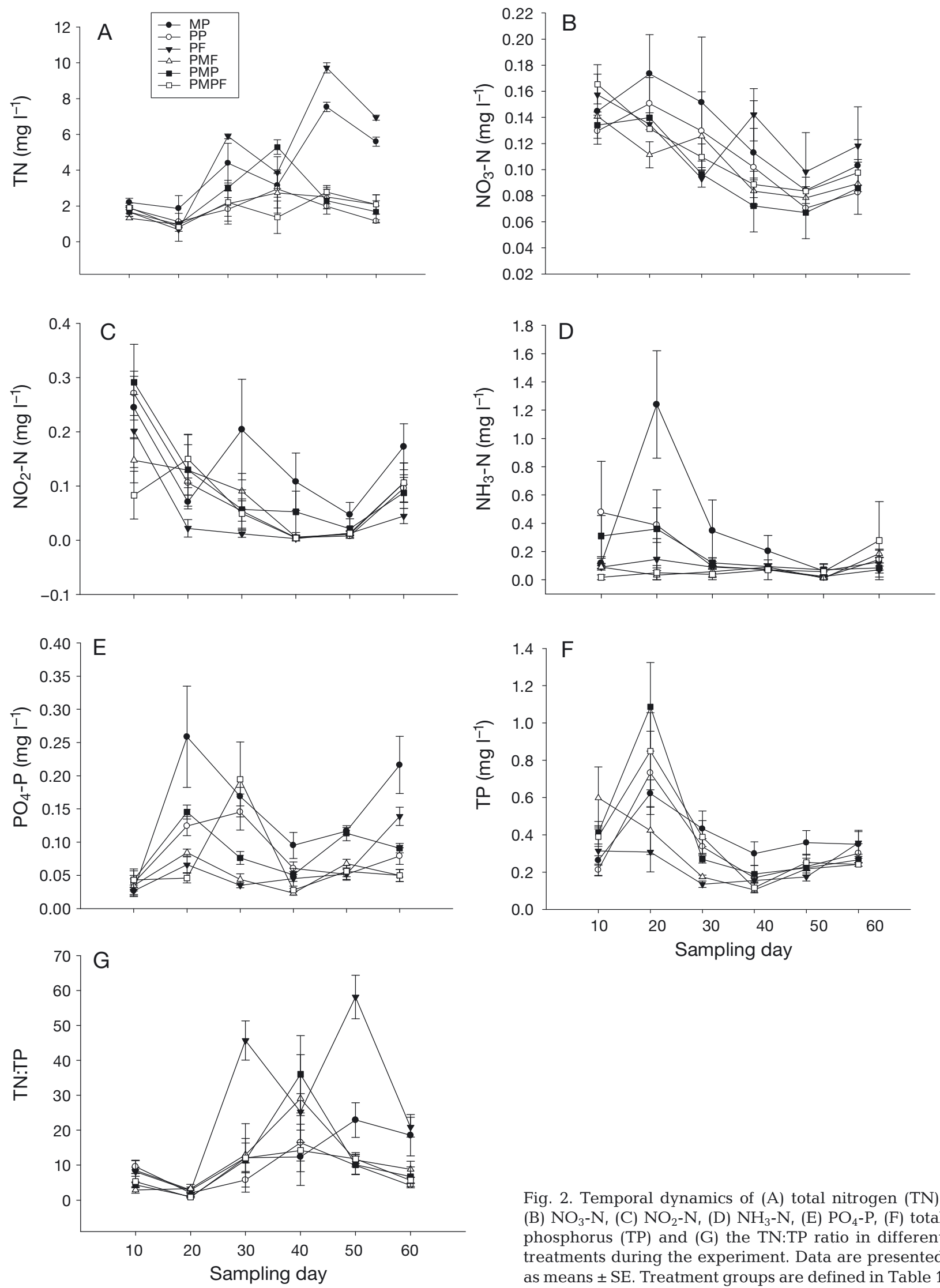

Fig. 2. Temporal dynamics of (A) total nitrogen (TN), (B) $\mathrm{NO}_{3}-\mathrm{N}$, (C) $\mathrm{NO}_{2}-\mathrm{N}$, (D) $\mathrm{NH}_{3}-\mathrm{N}$, (E) $\mathrm{PO}_{4}-\mathrm{P}$, (F) total phosphorus (TP) and (G) the TN:TP ratio in different treatments during the experiment. Data are presented as means \pm SE. Treatment groups are defined in Table 1 


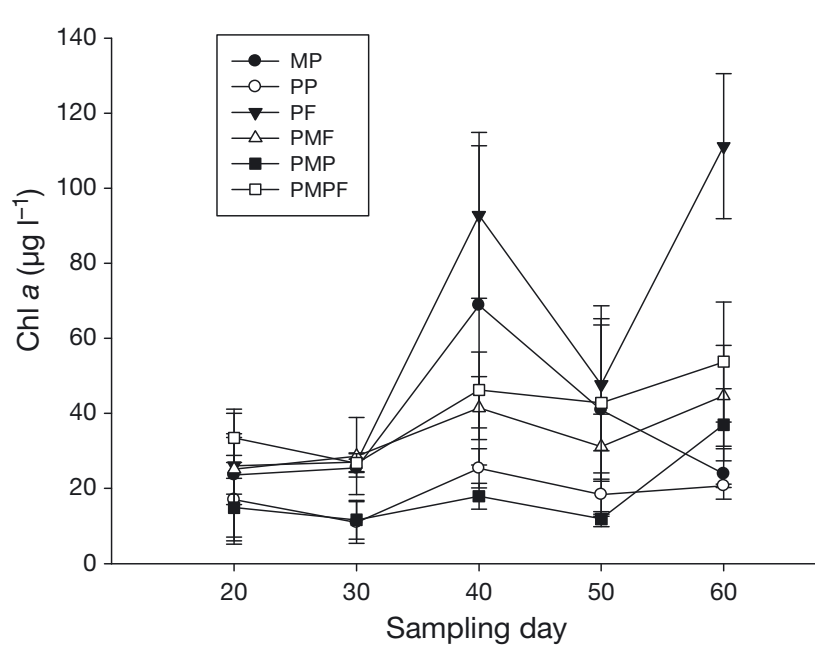

Fig. 3. Temporal dynamics of chlorophyll a in different treatments during the experiment. Data are presented as means \pm SE. Treatment groups are defined in Table 1

ence of Lemna minor and Hypophthalmichthys molitrix. L. minor may also have been a source of additional food and provided valuable refuges for $M$. rosenbergii. However, due to the relatively short period of the growth season we studied and the relatively large body sizes of the stocked $M$. rosenbergii, these differences were not significant. We found that $M$. rosenbergii often ate $L$. minor at night over the course of the experimental period, and that their survival rate was higher in the aquaculture treatments that included L. minor. Similar results have been reported by Cruz-Suárez et al. (2010), who showed that growth of the shrimp Litopenaeus vannamei was greatly improved when co-cultured with the green seaweed Ulva clathrata and provisioned with artificial feed. These authors suggested that Ulva spp. may act as a nutritional supplement and/or improve the utilization of nutrients from the artificial feed. In addition, Porchas-Cornejo et al. (1999) showed that the shrimp Farfantepenaeus californiensis can increase its growth rate 3 -fold in the presence of the alga Caulerpa sertularioides.

\section{Dynamics of water quality during the experiment}

Twenty days into the experiment, $\mathrm{PO}_{4}$ - $\mathrm{P}$ concentrations in all treatments, with the exception of the PMPF group, increased above $0.05 \mathrm{mg} \mathrm{l}^{-1}$, and continuous increases in the PP and PMPF groups were observed until Day 30. Peak values of TP in all groups occurred on Day 20, with the exception of the PF and PMF groups, and TN concentrations increased rapidly on Day 30. There was no fertilization and no sediment resuspension at the start of this experiment. Therefore, the rising concentrations of $\mathrm{TP}$, phosphorus and $\mathrm{TN}$ could be related to uneaten prawn food, feces from prawn or fish or as a result of the low phytoplankton biomass. These results were similar to those obtained in previous fish enclosure experiments (Kibria et al. 1997, Huang et al. 2016) which found that uneaten fish food and feces contained the majority of soluble reactive phosphorus (SRP). SRP has been shown to be the most available phosphorus fraction for phytoplankton growth (Peters 1981). In our study, phytoplankton biomass (indicated by chl a concentrations) enhanced rapidly on Day 40, especially in the PF group. At the same time, $\mathrm{N}$ and $\mathrm{P}$ concentrations decreased, with $\mathrm{NO}_{3}-\mathrm{N}$ concentrations also decreasing during the culture period. These data may be mainly attributed to the rapid uptake of $\mathrm{N}$ and $\mathrm{P}$ by phytoplankton.

\section{Effect of different treatments on water quality}

Filter-feeding fish can affect phytoplankton and zooplankton biomass by grazing and increase the loading of nutrients through excretion, sediment resuspension and simultaneous nutrient recycling (Lynch \& Shapiro 1981, Vanni \& Layne 1997). H. molitrix is one of the most intensively cultured fish species in China, and as a filter feeder, is often used in polyculture systems to maintain high water qual-

Table 3. Correlation coefficients between chlorophyll $a$ and water quality impact factors. Significant differences are indicated as ${ }^{*} \mathrm{p}<0.05,{ }^{* *} \mathrm{p}<0.01$. Treatment groups are defined in Table 1 ; water quality parameters are defined in Table 2

\begin{tabular}{|lllllrrrrr|}
\hline Group & DO & pH & $\mathrm{COD}_{\mathrm{Mn}}$ & $\mathrm{TOC}$ & $\mathrm{TP}$ & $\mathrm{TN}$ & $\mathrm{TN}: \mathrm{TP}$ & $\mathrm{PO}_{4}-\mathrm{P}$ & $\mathrm{NO}_{3}-\mathrm{N}^{2}$ \\
\hline MP & 0.011 & 0.185 & 0.342 & -0.255 & -0.349 & 0.014 & 0.150 & -0.418 & 0.226 \\
PP & -0.088 & $0.544^{*}$ & 0.225 & $-0.445^{*}$ & 0.126 & $0.806^{* *}$ & $0.523^{*}$ & 0.226 & -0.032 \\
PF & $0.500^{*}$ & 0.221 & 0.296 & -0.252 & -0.136 & -0.012 & 0.967 & -0.027 & 0.325 \\
PMF & $0.491^{*}$ & 0.205 & 0.008 & -0.314 & -0.199 & -0.168 & -0.051 & -0.238 & 0.155 \\
PMP & 0.096 & $0.582^{* *}$ & 0.169 & -0.114 & 0.026 & -0.161 & -0.035 & -0.114 & -0.106 \\
PMPF & 0.039 & $0.672^{*}$ & 0.459 & -0.538 & -0.390 & -0.066 & -0.103 & -0.229 & -0.459 \\
\hline
\end{tabular}


ity. Unfortunately, studies examining the effects of stocking $H$. molitrix on water nutrient loads in lake enclosure experiments have provided inconsistent results. Tang et al. (2002) reported that concentrations of TN and TP were significantly higher in enclosures with $H$. molitrix in Donghu Lake. In contrast, Guo et al. (2015) showed that TN concentrations in enclosures with $H$. molitrix were significantly lower than those in the surrounding lake (with lower densities of $H$. molitrix), although TP concentrations were higher in the enclosures. Differing from these lake enclosure experiments, artificial feeds were supplied daily to the $M$. rosenbergii enclosures in our study to enhance prawn production. $\mathrm{PO}_{4}-\mathrm{P}, \mathrm{TN}$ and $\mathrm{COD}_{\mathrm{Mn}}$ concentrations were all higher at the conclusion of our experiment than initial values. However, compared with the MP group, stocking with $H$. molitrix and Anodonta sp. decreased $\mathrm{PO}_{4}-\mathrm{P}$ concentrations after $20 \mathrm{~d}$ in the enclosures. These results were similar to those found in previous fish enclosure studies, where SRP concentrations dropped significantly in fish enclosures compared to fish-free controls (Lynch \& Shapiro 1981). This was likely a result of direct consumption by Anodonta sp. and H. molitrix, which are both filter feeders and ingest plankton, organic debris, bacterial agglomerates and other small particles out of the water. H. molitrix can also indirectly affect nutrient concentrations by controlling phytoplankton biomass. The effectiveness of filter-feeding fish at consuming phytoplankton biomass remains controversial (Zhang et al. 2006, Zhao et al. 2013, Guo et al. 2015, Yi et al. 2016). In the present study, chl a concentrations were highest in the treatments which stocked $H$. molitrix (PF, PMPF and PMF), which indicated that $H$. molitrix can improve the phytoplankton biomass. $H$. molitrix has a poor ability to filter phytoplankton smaller than $5 \mu \mathrm{m}$ (Ma et al. 2010), so the improved biomass was likely because $H$. molitrix can significantly suppress zooplankton biomass, after which zooplankton grazing becomes too low to suppress algal populations (Zhang et al. 2006, Zhao et al. 2013, Guo et al. 2015, Wang et al. 2016).

Compared with the PF group, mean chl $a$ and TN concentrations on Days 30,50 and 60 were lower in the PMF group, which were stocked with both Anodonta sp. and $H$. molitrix. These results suggested that Anodonta sp. can decrease chl $a$ and TN concentrations. Filter-feeding bivalves are capable of capturing substantial amounts of suspended material, including phytoplankton, which effectively removes and deposits considerable nutrient stores to the bottom waters in the form of feces or pseudofeces
(Haven \& Morales 1966, Cohen et al. 1984). As a result, filter-feeding shellfish are currently the primary species employed in open-water IMTA systems to extract particulate organic fish waste exiting fish net-pens (Cranford et al. 2013). For example, Zhang et al. (2004) indicated that Hyriopsis cumingii can significantly decrease $\mathrm{N}, \mathrm{P}, \mathrm{COD}$ and $5 \mathrm{~d}$ biochemical oxygen demand levels by 67.3, 73.2, 38.1 and 15.5, respectively.

L. minor has been used for wastewater treatment as a result of its capacity for rapid growth, strong anti-pollution performance and nutrient uptake ability, taking nitrogen and phosphorus up through both roots and fronds (Chong et al. 2006). Some studies have indicated that seaweeds can improve the water quality of shrimp ponds through biofiltering, thereby enhancing shrimp growth and health (Paul \& de Nys 2008, Copertino et al. 2009, Cruz-Suárez et al. 2010). In the present study, the prawn in the PMPF group experienced larger weight gains than those in the MP group. Furthermore, TN concentrations in the PP, PMP and PMPF groups decreased by 79.29, 70.00 and $70.54 \%$, respectively, compared to the MP group on Day 60. $\mathrm{PO}_{4}$ - $\mathrm{P}$ concentrations in the PP group also declined significantly between Day 40 and Day 60 . Overall, these results indicated that $L$. minor was able to efficiently uptake nitrogen and phosphorus.

\section{Correlations between chl $a$ and water quality parameters}

Phytoplankton play an important role in the material circulation and energy conversions within ponds. $\mathrm{Chl}$ a concentration is a widely used measure of phytoplankton biomass, often used as an indicator to evaluate the eutrophication of lakes. Many studies have shown that phytoplankton biomass is regulated by water quality parameters such as temperature, DO, $\mathrm{pH}$, nitrogen and phosphorus. However, the relationship between chl $a$ and these water quality parameters is inconsistent. For example, Jiang et al. (2010) demonstrated that chl $a$ is significantly linearly correlated with $\mathrm{COD}_{\mathrm{Mn}}$, TN and TP, positively correlated with DO and negatively correlated with $\mathrm{PO}_{4}$-P. Li et al. (2014) suggested that TN and TP were important factors impacting on chl a concentrations in ponds stocking $M$. rosenbergii. Hu et al. (2017) found that chl a was significantly correlated with DO and $\mathrm{pH}$, but not TP in all enclosures within the Xiaojiang River. In the present study, significant positive correlations were observed only between chl $a$ and DO for the PF and PMF groups, but not in the PP, 
PMP and PMPF groups. The DO in the PF and PMF groups mainly came from phytoplankton, but that of PP, PMP and PMPF groups came from not only phytoplankton but also $L$. minor, which might be a major reason why chl a was not correlated with DO in these groups stocking L. minor. These results indicated that the type of aquaculture system can influence whether correlations between chl $a$ and water quality parameters are present.

\section{CONCLUSION}

With respect to $M$. rosenbergii culture, the IMTA treatment PMPF showed the most superior performance for potential economic profits and ecological benefits compared with other treatments. Stocking with $H$. molitrix effectively reduced $\mathrm{P}$ concentrations within $M$. rosenbergii ponds in our study, but increased $\mathrm{N}$ and chl a concentrations. In contrast, stocking Anodonta sp. effectively reduced N concentrations within $M$. rosenbergii ponds. L. minor exhibited effective uptake of both $\mathrm{N}$ and $\mathrm{P}$ and significantly affected the correlations between chl $a$ and other water quality parameters. Further research is warranted to explore the full production potential of IMTA systems that incorporate PMPF and to optimize the proportion and size of each polyculture species.

Acknowledgements. This work was supported by Public Welfare Agriculture Research Special Project (no. 201203083), and Agricultural Science and Technology Guidance Project of Yancheng, China (YKN2014002).

\section{LITERATURE CITED}

Chong YX, Hu HY, Cui JH, Wu QT, Qian Y (2006) Application of duckweeds in wastewater treatment. Tech Equip Environ Pollut Control 7:14-18 (in Chinese)

Chopin T, Buschmann AH, Halling C, Troell M and others (2001) Integrating seaweeds into marine aquaculture systems: a key toward sustainability. J Phycol 37: 975-986

Cohen RRH, Dresler PV, Phillips EJP, Cory RL (1984) The effect of the Asian clam, Corbicula fluminea, on phytoplankton of the Potomac River, Maryland. Limnol Oceanogr 29:170-180

Copertino MDS, Tormena T, Seeliger U (2009) Biofiltering efficiency, uptake and assimilation rates of Ulva clathrata (Roth) J. Agardh (Clorophyceae) cultivated in shrimp aquaculture waste water. J Appl Phycol 21:31-45

* Costanzo SD, O'Donohue MJ, Dennison WC (2004) Assessing the influence and distribution of shrimp pond effluent in a tidal mangrove creek in north-east Australia. Mar Pollut Bull 48:514-525

* Cranford PJ, Reid GK, Robinson SMC (2013) Open water integrated multi-trophic aquaculture: constraints on the effectiveness of mussels as an organic extractive component. Aquacult Environ Interact 4:163-173

* Cruz-Suárez LE, León A, Peña-Rodríguez A, RodríguezPeña G, Moll B, Ricque-Marie D (2010) Shrimp/Ulva coculture: a sustainable alternative to diminish the need for artificial feed and improve shrimp quality. Aquaculture 301:64-68

FAO (2006) State of world aquaculture. Fish Tech Pap 500. FAO, Rome

FAO (2009) Integrated mariculture: a global review. Fish Aquacult Tech Pap 529. FAO, Rome

FAO (2012) Fisheries statistical database, global aquaculture production. www.fao.org/fishery/statistics/globalaquaculture-production/en

Guo LG, Wang Q, Xie P, Tao M, Zhang J, Niu Y, Ma ZM (2015) A non-classical biomanipulation experiment in Gonghu Bay of Lake Taihu: control of Microcystis blooms using silver and bighead carp. Aquacult Res 46:2211-2224

Haven DS, Morales AR (1966) Aspects of biodeposition by oysters and other invertebrate filter feeders. Limnol Oceanogr 11:487-498

* Hu L, Yang Z, Pan X, Zhao N, Peng J, Wan C (2017) Use of fish species from different trophic levels to control algae and water quality: an enclosure experiment in eutrophic area of Xiaojiang River. PLOS ONE 12:e0171953

*Huang SL, Wu M, Zang CJ, Du SL and others (2016) Dynamics of algae growth and nutrients in experimental enclosures culturing bighead carp and common carp: phosphorus dynamics. Int J Sediment Res 31:173-180

Jackson C, Preston N, Thompson PJ, Burford M (2003) Nitrogen budget and effluent nitrogen components at an intensive shrimp farm. Aquaculture 218:397-411

Jiang M, Yu GD, Dai XL, Liu LP, Gu DP, Hu WG, Diana JS (2010) Multivariate statistical analysis of chlorophyll a and water quality parameters in ponds of Litopenaeus vannamei culturing. J Fish China 34:1712-1718

Jin XS, Tu QY (1990) The investigation standard of lake eutrophication. Environmental Science Press, Beijing (in Chinese)

Kibria G, Nugegoda D, Fairclough R, Lam P (1997) The nutrient content and the release of nutrients from fish food and faeces. Hydrobiologia 357:165-171

Li SK, Jiang M, Pan RL, Dai XL, He L (2014) Gray correlation analysis of chlorophyll a with water quality factors in Macrobrachium rosenbergii ponds. J Ecol Rural Environ 30:257-261

Liu QG, Tang YT, Yu ZJ, Zhang GF (2014) Experimental study on structure optimization for polyculture of giant freshwater prawn with triangle sail mussel, silver carp and bighead carp. J Fish China 38:1855-1864

Lynch M, Shapiro J (1981) Predation, enrichment and phytoplankton community structure. Limnol Oceanogr 26: 86-102

* Ma H, Cui FY, Liu ZQ, Fan ZQ, He WJ, Yin PJ (2010) Effect of filter-feeding fish silver carp on phytoplankton species and size distribution in surface water: a field study in water works. J Environ Sci (China) 22:161-167

Neori A, Chopin T, Troell M, Buschmann AH and others (2004) Integrated aquaculture: rationale, evolution and state of the art emphasizing seaweed biofiltration in modern mariculture. Aquaculture 231:361-391

* Paul NA, de Nys R (2008) Promise and pitfalls of locally abundant seaweeds as biofilters for integrated aquaculture. Aquaculture 281:49-55 
Peters RH (1981) Phosphorus availability in Lake Memphremagog and its tributaries. Limnol Oceanogr 26: 1150-1161

Porchas-Cornejo MA, Martinez-Cordova LR, Barajas FM, Paramo JN, Clark GP (1999) Effect of the macroalga Caulerpa sertularioides on the development of Penaeus californiensis shrimp (Decapoda: Peneidae). Rev Biol Trop 47:437-442

Ramos R, Vinatea L, Seiffert W, Beltrame E, Silva JS, Ribeiro da Costa RH (2009) Treatment of shrimp effluent by sedimentation and oyster filtration using Crassostrea gigas and C. rhizophorae. Braz Arch Biol Technol 52:775-783

Sansanayuth P, Phadungchep A, Ngammontha S, Ngdngam S, Sukasem P, Hoshino H, Ttabucanon MS (1996) Shrimp pond effluent: pollution problems and treatment by constructed wetlands. Water Sci Technol 34:93-98

Sun Y, Li J, Cui Y, Li F (1997) Dissolving rates of N and P from newborn remains produced by feeding and their changing patterns in shrimp pond. Chin J Appl Ecol 8: 541-544 (in Chinese)

Tang HJ, Xie P, Lu M, Xie LQ, Wang JA (2002) Studies on the effects of silver carp (Hypophthalmichthys molitrix) on the phytoplankton in a shallow hypereutrophic lake through an enclosure experiment. Int Rev Hydrobiol 87:107-119

Vanni MJ, Layne CD (1997) Nutrient recycling and herbivory as mechanisms in the 'top-down' effect of fish on algae in lakes. Ecology 78:21-40

Wang YP, Gu XH, Zeng QF, Mao ZG, Wang WX (2016) Con-

Editorial responsibility: Megan La Peyre,

Baton Rouge, Louisiana, USA trasting response of a plankton community to two filterfeeding fish and their feces: an in situ enclosure experiment. Aquaculture 465:330-340

Yi CL, Guo LG, Ni LY, Luo CQ (2016) Silver carp exhibited an enhanced ability of biomanipulation to control cyanobacteria bloom compared to bighead carp in hypereutrophic Lake Taihu mesocosms. Ecol Eng 89:7-13

* Yuan D, Yi Y, Yakupitiyage A, Fitzimmons K, Diana JS (2010) Effects of addition of red tilapia (Oreochromis spp.) at different densities and sizes on production, water quality and nutrient recovery of intensive culture of white shrimp (Litopenaeus vannamei) in cement tanks. Aquaculture 298:226-238

* Zhang GF, Deng MZ, Fang AP (2004) The effects of cocultivation of pearl mussels and fishes on water pollution control in middle or small sized water. Chin J Oceanology Limnol 22:425-430

Zhang X, Xie P, Hao L, Guo N and others (2006) Effects of the phytoplanktivorous silver carp (Hypophthalmichthys molitrixon [sic]) on plankton and the hepatotoxic microcystins in an enclosure experiment in a eutrophic lake, Lake Shichahal in Beijing. Aquaculture 257:173-186

Zhang ZS, Huang YF (1995) Methods for the plankton study in freshwater. Science Press, Beijing (in Chinese)

Z Zhao SY, Sun YP, Lin QQ, Han BP (2013) Effects of silver carp (Hypophthalmichthys molitrix) and nutrients on the plankton community of a deep, tropical reservoir: an enclosure experiment. Freshw Biol 58:100-113

Submitted: May 11, 2018; Accepted: September 26, 2018 Proofs received from author(s): December 3, 2018 